\title{
Towards More Resilient Conservation Practices: Bridging the Past and Present of Human-Wildlife Interactions
}

\author{
Beatrice Frank 1,2,*(D) and Brandon P. Anthony ${ }^{3}$ (D) \\ 1 Capital Regional District, Regional Parks, Victoria, BC V9B 2Z8, Canada \\ 2 School of Environmental Studies, University of Victoria, Victoria, BC V9B 2Z8, Canada \\ 3 Department of Environmental Sciences \& Policy, Central European University, A-1100 Vienna, Austria; \\ anthonyb@ceu.edu \\ * Correspondence: bfrank@crd.bc.ca
}

Citation: Frank, B.; Anthony, B.P. Towards More Resilient Conservation Practices: Bridging the Past and Present of Human-Wildlife Interactions. Sustainability 2021, 13, 12131. https://doi.org/10.3390/ su132112131

Received: 16 October 2021

Accepted: 26 October 2021

Published: 3 November 2021

Publisher's Note: MDPI stays neutral with regard to jurisdictional claims in published maps and institutional affiliations.

Copyright: (c) 2021 by the authors. Licensee MDPI, Basel, Switzerland. This article is an open access article distributed under the terms and conditions of the Creative Commons Attribution (CC BY) license (https:// creativecommons.org/licenses/by/ $4.0 /)$.

\section{Introduction}

Human-wildlife interactions (HWI), whether they be conflict to coexistence situations, are widely researched and described in the literature, as shown by the flourishing of HWI publications over the past 20 years [1]. Human-wildlife conflict (HWC) is defined as negative interactions between humans and wildlife, or between humans and humans over wildlife and its management [2,3], while human-wildlife coexistence infers that humans and wildlife prosper together and/or co-adapt while sharing landscapes and resources [1-4]. Because of the complexity of HWI and the potential backlash such interactions can have on biodiversity conservation, researchers have increasingly moved from a conflict focus to the inclusion of coexistence lexicon and approaches in conservation $[1,3,5]$, all in an attempt to widen the array of solutions to address HWI in multifaceted and multi-stakeholder settings. While definitions have evolved and the understanding around HWI has deepened through research efforts, the line between what represents a conflict or coexistence interaction has remained blurred, as the relationships between humans and wildlife are dynamic, change over time, and may be perceived differently based on inter alia culture, location, severity, and the institutional architecture in place to manage conflicts $[3,5,6]$. As HWI are increasing in many parts of the world [4,7], their complexity is becoming even more intractable as charismatic species, multiple stakeholders, clashing values, and varied institutional and governance arrangements are involved. This complexity can be exacerbated when societal issues are present and perpetuated, such as deep-rooted inequalities and social injustices [8].

In our Special Issue "Finding Long Term Resolutions to Human-Wildlife Conflicts", we look beyond strict conflicts and embrace the wider spectrum of HWI by recognizing the need to consider a cohort of diverse voices, interests, human-human interactions, and socio-ecological dimensions in wildlife conservation and management. We advocate for more inclusive bottom-up decision-making processes that are transparent and crafted with local communities and stakeholders, in order to develop shared responsibility and ownership over the governance of wildlife, and that address multiple and related societal issues. To achieve this goal, we have asked the contributors to this issue to reflect on the following questions:

- What factor(s) determine 'success' or 'failure' of interventions to mitigate negative and/or enhance positive human-wildlife interactions?

- What factor(s) are critical to maintain/enhance lasting coexistence between people, wildlife, and management structures?

- What recommendations can be applied to other HWI in similar contexts that can enhance successful conflict resolution?

- What innovative and 'out of the box' solutions can be pursued or 'borrowed' from other disciplines to shift from conflict to coexistence between humans and wildlife? 
Nowadays, it is largely recognized that strengthening the understanding regarding the interface between community-based needs, policy, and practice in regards to HWI is pivotal for enabling more resilient and innovative conservation practices that are able to withstand changing and ever-evolving HWI and the internal turmoil that human-human conflict about and over wildlife can ignite $[9,10]$. However, public engagement about wildlife management and conservation has often narrowly focused on the proximate issues currently affecting stakeholders and communities, ignoring the underlying narratives that shape HWI discourses in the first place [11,12]. To address this gap, narratives are used in this Special Issue to frame both the problems and solutions to HWI, considering historical lenses and multiple sources of knowledge. Narratives, defined as discourses having a clear beginning, often a complicated middle, and, in the best-case scenario, an ending with a resolution (Table 1, see article 1), allow the development of a more holistic and in-depth understanding of HWI. Narratives, which are simplified explanations about the world and how it works in relation to environmental and social causes and effects, can help shape human understanding and guide policy, practice, and action $[13,14]$. They can also clarify the history and socio-economic context of an area and, thus, can reveal "the agendas of different actors regarding landscape values" [15] (p. 84). Furthermore, narratives have a transformative potential when they combine multiple sources of knowledge because they allow for a more critical reflection about, and a deeper understanding of, multifaceted conservation issues, such as those ignited by HWI [16]. More importantly, narratives are developed in compliance with humans' ethical and social systems and are applied by stakeholders and communities to frame problems and solutions [14], hence their importance in HWI discourses.

Table 1. Special Issue Contribution.

\begin{tabular}{ccc}
\hline Article & Authors & Title \\
\hline & $\begin{array}{c}\text { Köpke, S.; Withanachchi, S.S.; Pathiranage, R.; Withanachchi, } \\
\text { C.R.; Gamage, D.U.; Nissanka, T.S.; Warapitiya, C.C.; } \\
\text { Nissanka, B.M.; Ranasinghe, N.N.; Senarathna, C.D.; et al. }\end{array}$ & $\begin{array}{c}\text { Human-elephant conflict in Sri Lanka: A critical } \\
\text { review of causal explanations. }\end{array}$ \\
\hline \multirow{2}{*}{$\begin{array}{c}\text { Garrido Corredor, A.M.; Cottyn, H.; Martínez-Medina, S.; } \\
\text { Wheatley, C.J.; Sanchez, A.; Kirshner, J.; Cowie, H.; } \\
\text { Touza-Montero, J.; White, P.C.L. }\end{array}$} & $\begin{array}{c}\text { Oso, Osito ¿A Qué Venís? Andean bear conflict, } \\
\text { conservation, and campesinos in the } \\
\text { Colombian páramos }\end{array}$ \\
\hline & Anthony, B.P. & $\begin{array}{c}\text { Paying for the past: The importance of fulfilling } \\
\text { promises as a key component to resolving } \\
\text { human-wildlife conflict }\end{array}$ \\
\hline & $\begin{array}{c}\text { Young, J.C.; Alexander, J.S.; Bijoor, A.; Sharma, D.; Dutta, A.; } \\
\text { Agvaantseren, B.; Mijiddorj, T.N.; Jumabay, K.; Amankul, V.; } \\
\text { Kabaeva, B.; et al. }\end{array}$ & $\begin{array}{c}\text { Community-based conservation for the sustainable } \\
\text { management of conservation conflicts: Learning } \\
\text { from practitioners }\end{array}$ \\
\hline
\end{tabular}

Approaches designed and implemented to address current HWI often lack thoughtful consideration of the multifaceted practices and relationships that have led to specific narratives about HWI. Using narrow narratives to address HWI can enhance conflict and lead to ineffective engagement that perpetuates injustices toward communities living with wildlife, as showcased in "Human-Elephant Conflict in Sri Lanka: A Critical Review of Causal Explanations" (Table 1, see article 1). Underlying narratives are traced in this contribution by exploring how elephant-human interactions have been shaped by Sri Lanka's early independent kingdoms, and then by colonial control through Portuguese, Dutch and British domination. Those narratives are weaved into the description of how human population growth and modern land-use practices implemented by Sri Lanka's state, which owns $80 \%$ of the land surface, have led to a loss of traditional agricultural practices, habitat degradation and fragmentation, an increase in problem elephants and crop-raiding, and exclusionary conservation practices. Those are deemed to be a consequence of a complex historical development process framed in a colonial legacy that has ignored past long-term socio-ecological dynamics where humans and elephants had co-adapted. Addressing 
current elephant-human interactions without considering this narrative has led to misinterpretations of the current socio-economic vulnerabilities of local communities living with this megaherbivore, causing even more socio-economic grievances and hostility of the affected communities towards elephants. Through this contribution narrative, the authors stress the need for "reflection on human-wildlife encounters' history, geography, ecology and politics" (p. 2) (Table 1, see article 1), and highlight how narrow narratives, focused only on the present, may ignore wider socio-economic vulnerabilities and hinder the development of conservation practices that foster human-elephant coexistence.

Building on the importance of narratives behind HWI in connection with policies, places, institutions, and past trajectories, Corredor et al. (Table 1, see article 2) explore the historically co-constructed landscape of the páramos around Colombia's capital city of Bogotá, and the "multispecies entanglements" between campesino (the rural working class) and Andean bears (Tremarctos ornatus). In "Oso, osito ¿a qué venís? Andean Bear Conflict, Conservation and Campesinos in the Colombian Páramos", the authors describe how human-bear interactions have been shaped over time by public utilities, environmental and conservation institutions, cattle ranching and agriculture practices, past violence and political conflict, and scientific research. This narrative elucidates how the dynamics of exclusion and friction between stakeholders with different decision-making power over the páramos have influenced local human-bear relationships over time. From the bear being part of the cultural identity and embedded within local communities in this rural Colombian landscape, it has become disconnected and now plays the role of a "participant" in the displacement and perpetuation of injustices against campesino. Ignoring such multifaceted narratives may lead to a simplification of HWI in the páramos context, enhancing the risk of reproducing conflicts, perpetuating injustices, and reducing the resiliency of any conservation practice.

Narratives of broken promises and the historic undermining of the wellbeing of local communities in relation to HWC is the central theme of "Paying for the Past: The Importance of Fulfilling Promises as a Key Component to Resolving Human-Wildlife Conflict" (Table 1, see article 3). The lack of compensation to communities affected by damagecausing animals escaping from Kruger National Park, South Africa, frames the locals' mistrust towards, and tense relationships with, conservation agencies. Community resentment, however, cannot be fully understood if it is narrowly focused on HWC. By using multiple sources of knowledge, and merging insights from archival research, interviews, and focus groups, the author unravels how some promises made by authorities about HWC have been repeatedly broken over the years. Having a deeper understanding of such a narrative has allowed park authorities to address the past negative impacts and unfulfilled promises with communities, in part, through the co-development of a new compensation system that addresses both past and present HWC [17]. By understanding the beginning and middle of narratives, and aiming at an ending with a resolution, park authorities may be able to rebuild local relationships, trust, and legitimacy in conservation practices.

"Community-Based Conservation for the Sustainable Management of Conservation Conflicts: Learning from Practitioners" by Young et al. (Table 1, see article 4) goes a step further in showcasing how narratives can be used on the ground to assess and improve conservation efforts. In this last contribution, conservation practitioners working on human-snow leopard interactions in Kyrgyzstan, India, Pakistan, and Mongolia were invited to write narratives about their own HWI experiences. These narratives were then evaluated and discussed in light of the inclusive conservation framework for effective and ethical engagement, developed by the Snow Leopard Trust and their partners, called "PARTNERS Principles" (presence, aptness, respect, transparency, negotiation, empathy, responsiveness, and strategic support). Documenting the narratives of conservation practitioners about their HWI management and community-based conservation, the authors identified presence, respect, and empathy as key principles for building resilient conservation practices across their case studies. It also provided a multifaceted and in-depth 
narrative concerning human-snow leopards interactions; a narrative that can help develop long-term perspectives, innovative conservation practices, and more engaged communities.

\section{Moving towards More Resilient and Innovative Conservation Practices}

We believe that HWC and HWI researchers and practitioners have much to learn from these four contributions and the underlying narratives that tie together these examples of complex and multifaceted human-wildlife dynamics. All the contributions in this Special Issue showcase the importance of developing narratives through multidisciplinary lenses, which helps to overcome disciplinary silos and facilitates approaches to seemingly intractable problems with wider and deeper understanding. All the contributors, indeed, went beyond just looking at the HWI issue at hand by including historical, cultural, geographical, governance and ecological lenses, to obtain a rich and in-depth informed and pluralistic narrative. Each lens of the narrative is a stand-alone piece of a puzzle that aptly explains a specific issue. Yet, by putting all those puzzle pieces—or disciplinary lensestogether, a clearer and broader image emerges; an image that is richer and more suitable to prompt innovative solutions. The authors go a step further by showing the need of developing more tangible collaboration across disciplinary boundaries, to understand contexts and stress the importance of including all relevant stakeholders, while building visions and responsibilities towards biodiversity conservation and management. Understanding the varied stakeholders' narratives and then weaving them together through collaborations can create common ground, empathy, and a willingness to become involved and take action in biodiversity conservation. A more inclusive approach can, indeed, lead to more effective and ethical engagement with local communities and stakeholders, generating resilient relationships among all interested parties. The final contribution of the authors, the one we feel is the most powerful, is refraining from limiting research to descriptive studies that simply dissect a problem without offering plausible solutions and/or mitigation approaches. From the first to the last contribution in this Special Issue, we showcase how narratives helped our authors to move from a more passive and descriptive research approach to a more hands on and solution-oriented lens, one that can help 'science' connect more broadly to 'society'.

We acknowledge that HWI are highly dependent on the type of co-occurrence between wildlife, communities, and other stakeholders, as well as from embedded socio-cultural and traditional practices and narratives [1,3]. We also acknowledge that many communities and stakeholders, while struggling with different challenges, have already developed innovative approaches and become leaders in managing and regenerating biodiversity [3]. We hope, through this contribution, to further inspire durable and equitable solutions that allow human societies and wildlife to thrive together through more resilient conservation practices that are supported by collaborative and transdisciplinary training, research, and solution-oriented approaches. We envision this Special Issue as just the start of an engaged and broader discussion among HWI researchers, practitioners, communities, and many other interested parties on the importance of narratives in shaping the dynamic and everchanging relations between humans and wildlife as, often, those hidden and longstanding narratives are the ones making an HWI a conflict or coexistence situation. By having a clear understanding of the beginning of the HWI narrative, it will be possible to address the complicated middle of the human-wildlife dynamic at hand and, thus, thrive for an ending with a resolution that is long lasting, resilient, equitable, and just for all - a necessary step when aiming at successful biodiversity management and conservation.

Author Contributions: Both editors contributed equally to writing the editorial. All authors have read and agreed to the published version of the manuscript.

Funding: This research received no external funding.

Institutional Review Board Statement: Not applicable.

Informed Consent Statement: Not applicable. 
Data Availability Statement: No data are available as this editorial does not present any results from research.

Conflicts of Interest: The authors declare no conflict of interest.

\section{References}

1. König, H.; Kiffner, C.; Kramer-Schadt, S.; Fürst, C.; Keuling, O.; Ford, A. Human-wildlife coexistence in a changing world. Conserv. Biol. 2020, 34, 786-794. [CrossRef] [PubMed]

2. Frank, B. Human-wildlife conflicts, the need to include tolerance and coexistence: An introductory comment. Soc. Nat. Res. 2016, 29, 738-743. [CrossRef]

3. Frank, B.; Glikman, J.A.; Marchini, S. Human-Wildlife Interactions: Turning Conflict into Coexistence; Cambridge University Press: Cambridge, UK, 2019.

4. Carter, N.H.; Linnell, J.D.C. Co-adaptation is key to coexisting with large carnivores. Trends Ecol. Evol. 2016, 31, 575-578. [CrossRef] [PubMed]

5. Glikman, J.A.; Frank, B.; Ruppert, K.A.; Knox, J.; Sponarski, C.C.; Metcalf, E.C.; Metcalf, A.L.; Marchini, S. Coexisting with different human-wildlife coexistence perspectives. Front. Conserv. Sci. 2021, 2, 75. [CrossRef]

6. Anthony, B.P.; Scott, P.; Antypas, A. Sitting on the fence? Policies and practices in managing human-wildlife conflict in Limpopo Province. S. Afr. Conserv. Soc. 2010, 8, 225-240. [CrossRef]

7. Chapron, G.; Kaczensky, P.; Linnell, J.D.C.; von Arx, M.; Huber, D.; Andrén, H.; López-Bao, J.V.; Adamec, M.; Álvares, F.; Anders, O.; et al. Recovery of large carnivores in Europe's modern human-dominated landscapes. Science 2014, 346, 1517-1519. [CrossRef] [PubMed]

8. Jordan, N.R.; Smith, B.P.; Appleby, R.G.; van Eeden, L.M.; Webster, H.S. Addressing inequality and intolerance in human-wildlife coexistence. Conserv. Biol. 2020, 34, 803-810. [CrossRef] [PubMed]

9. Dietsch, A.M.; Wald, D.M.; Stern, M.J.; Tully, B. An understanding of trust, identity, and power can enhance equitable and resilient conservation partnerships and processes. Conserv. Sci. Pract. 2021, 3, e421.

10. McMurdo Hamilton, T.; Canessa, S.; Clarke, K.; Gleenson, P.; Mackenzie, F.; Makan, T.; Moses-Te Kani, G.; Oliver, S.; Parker, K.A.; Ewen, J.G. Applying a values-based decision process to facilitate co-management of threatened species in Aotearoa New Zealand. Conserv. Biol. 2020, 35, 1162-1173. [CrossRef] [PubMed]

11. Madden, F.; McQuinn, B. Conservation's blind spot: The case for conflict transformation in wildlife conservation. Biol. Conserv. 2014, 178, 97-106. [CrossRef]

12. Madden, F.; McQuinn, B. Conservation Conflict Transformation: The Missing Link in Conservation. In Understanding Conflicts about Wildlife: A Biosocial Approach; Hill, C.M., Webber, A.D., Priston, N.E.C., Eds.; Berghahn Books: New York, NY, USA, 2017; Volume 9, pp. 148-169.

13. Forsyth, T.; Walker, A. Forest Guardians, Forest Destroyers: The Politics of Environmental Knowledge in Northern Thailand. Culture, Place, and Nature: Studies in Anthropology and Environment Series; University of Washington Press: Seattle, WA, USA, 2008 ; p. 302.

14. Zinngrebe, Y.M. Conservation narratives in Peru: Envisioning biodiversity in sustainable development. Ecol. Soc. 2016, 21, 35. [CrossRef]

15. Aastrup, M.L. Conservation narratives and conflicts over protected areas in post-socialist Romania. J. Political Ecol. 2020, 27, 84-104. [CrossRef]

16. Louder, E.; Wyborn, C. Biodiversity narratives: Stories of the evolving conservation landscape. Environ. Conserv. 2020, 47, 251-259. [CrossRef]

17. Anthony, B.P.; Swemmer, L. Co-defining program success: Identifying objectives and indicators for a livestock damage compensation scheme at Kruger National Park, South Africa. J. Nat. Conserv. 2015, 26, 65-77. [CrossRef] 